\title{
THE PORTFOLIO - A GOOD EDUCATIONAL PRACTICE (A REVIEW OF PUBLICATIONS)
}

\author{
Z. Zhelyazkova* \\ Faculty of Education, Trakia University, Stara Zagora, Bulgaria
}

\begin{abstract}
The paper is a review article devoted to a brief overview of English-language publications on portfolio as a good tool for continuously improving the quality of education in secondary and higher-education schools. The study is an essential part of the activities of a research project aimed at creating an electronic institutional portfolio of the specialty Social Pedagogy - at the Faculty of Education, Trakia University - Stara Zagora; respectively, the method used is qualitative critical review. The intention of the project is practically justified by the need to present a university specialty to various users - present and potential students, alumni, employers and other business environments of social and educational services, partner institutions, including mentors of student placement practices, national and foreign and/or international corporative non-profit associations with a similar scope of educational activities sharing the same interest in the specialty for working in a net.
\end{abstract}

Key words: quality of university education, life skills, academic experience, prospective professional realization

\section{POSITIVE EFFECTS AND LIMITATIONS OF ELECTRONIC PORTFOLIOS}

Among the most common examples of good practices related to portfolios are practices that, according to research, contribute to opportunities for students to study in internships, participate in undergraduate research, learning communities and joint training. Such platforms provide numerous opportunities for improving communications within the institution; development of the academic staff; administrative practices that support the quality of education and prepare students for their professional life. All this is done with the availability of technology based on cross-functional instruction and environment which is beneficial for the studying of students in and out of the university auditoriums.

Invariably, however, in order to successfully run such a project, some additional commitments for the administrative staff and academic community are superimposed: they

\footnotetext{
*Correspondence to: Zlatka Zhelyazkova, PhD, email-zlato6ki@abv.bg, 9 'Armeiska’Str., St. Zagora 6010
}

have to be trained to master the skills needed to work with sets such as web programming (if the institutional portfolio is electronic), a possible upgrade of the technological infrastructure, software costs, etc.

As negative side effects that require special attention to risk management we can determine several of the already well-known characteristics of the online tools in general and of the institutional portfolio in particular:

$>$ issues related to security and privacy;

$>$ the need to spare extra time in the faculty for staff and students, which time is normally not accredited but is taken from their personal time.

All authors, however, agree that the advantages which the creation of an institutional portfolio brings to the institution are indisputable. Among the most frequently cited positive effects are the following:

$>$ the institutional portfolio enables communication through its mission and results;

$>$ it allows faculty academic and administrative staff to formulate in an easily-accessible form its activities and 
services in connection with the institutional mission;

$>$ it assists potential students and their families when making a choice for a specialization in a higher educational institution;

$>$ the portfolio continuously updates the data for the institutional effectiveness;

$>$ it allows for the use of some "invisible" for the students tools, thereby the overcoming of problems with motivation and other relevant issues related to examination format practices and so on;

$>$ saves time form the academic load, etc.

The best practices show that for the institutional portfolio to gain its own worth and meaning, it is necessary to clearly distinguish it from the other services related to the university technologies, such as the website of the university, the faculty, etc. (1).

\section{DEFINING THE TERM "INSTITUTIONAL PORTFOLIO"}

The main components of institutional portfolios, which is of interest in this material, in its Bulgarian projection, practice and perspective, have been formulated in the first of its kind in our country institutional portfolio in education - that of the Department for Information and Training of Teachers at Sofia University (2010). There are three main functional components connected in a single structure: 1) instrumental practice presenting the institution in the form of a collection of its products; 2) a sign of recognition of the product quality and 3) industrial production of evidence. The use of portfolio in education dates back to the 80s of the 20th century in the American educational system. In the last decade the practice of the portfolio is proving particularly useful and applicable within the European Union and the Council of Europe, especially as a European Language Portfolio, used for mobility and mutual recognition of language skills. The strategy and program of the management team of the Department for Information and Training of Teachers are based on the modern understanding of organizational management, which includes marketing, public communication, institutional openness, dialogue and transparency, predictability and reliability of the activities of the Department as a recognized university department for continuing education of pedagogical specialists. An effective tool for providing the management program is the institutional portfolio. The portfolio documents the history of the department, its mission and vision of the institution as a corporate entity; it also documents the internal dynamics and inter-institutional progress and outlines the prospects in the department's stability. The portfolio committed the members of the department team to actively maintain their competence. It functions as a protective mechanism against disloyalty and incorrectness, on the one hand, and as a guarantor of professional ethics and creative communication, on the other (2).

Institutional portfolios could be described as a complex of several measures demonstrating that the results of the mission and training defined by the institution are realized. This is a tool that serves to disseminate the results of training for internal and external users, and also serves as a tool for learning. Institutional portfolios demonstrate accountability to the stakeholders and can be used as a tool for the entire institution for reflection, learning and improvement. One institutional portfolio is a purposeful selection of authentic developments, data and analysis. The main categories that are included are: direct training measures, such as test results, estimates of authentic materials and student portfolios.

The inclusion of a broad technological base and human resources, available to the institution, increases the likelihood that the project will be supported and helpful and that the invested expectations will be justified. There could not be a common template for an institutional portfolio, but rather a working model of the design. It is necessary that the institution develops its own model for the organization and presentation of their platform. In order to determine the contents of the portfolio, a functional needs assessment needs to be made and determining what organizational structure and responsibilities will be needed is required.

\section{OVERVIEW OF THE PRACTICES FOR AN INSTITUTIONAL PORTFOLIO}

Education in the 21 st century is predominantly electronically based.

The interest of the study is directed towards the variety of portfolio models, transactions and other practices in the field of university education on the international scene today.

An interesting starting point for the practice of the portfolio in the Norwegian higher education is the so called "chameleon" aspect of the portfolio. Recently, a study of the contextual nature of this diversity called "chameleon aspect" based on the example of the Norwegian higher education was performed. The aim was to explore the effects at a macro-level, especially those related to the 
Bologna reform of the quality and of the overall development of portfolio practices. This shows the basic function of the practice portfolio in the educational field - for management of the quality of education. It was found that most of the portfolios in the Norwegian universities are classified as "discipline-based coursework" and they usually serve for training purposes, including work evaluation. At the same time, systematic differences between the different educational areas are registered in which the main dividing line is between the professional portfolio and that of the general education. This directs the research to the socio-cultural perspective and to issues, cultures and traditions in which the development of the form of the portfolio loses its individual characteristics (the so-called "micro level") (3).

Another successful system, whose experience stands out traditionally, is the North American one. The North American Association for Higher Education (Washington, State of Colombia) identifies seven principles of application of the student portfolio that can help improve higher education. Based on research on university teaching and learning, it was found that the best practices of portfolios in higher education are those which: 1) encourage the contacts between students and teachers; 2) develop reciprocity and cooperation among students; 3 ) use techniques for active learning; 4) provide rapid feedback; 5) explicitly acknowledge the time for the task; 6) communicate high expectations and 7) respect diverse talents and different styles and ways of life. Among the examples of good approaches, included in the study, are: seminars conducted by freshmen on important topics taught by senior faculty members; study groups of five to seven students who meet regularly during the semester to solve the problems posed by the teachers; active learning through structured exercises, discussions, team projects and peer critiques, as well as internships and independent research; the so-called "master training", contracted learning and computeraided instructional approaches that require sufficient time to learn (4).

In another American study of the contents of the portfolio - the University of California - it was found that whether accomplished in the classroom, in the lab, at work or overtime, on the campus of the university or elsewhere, one of the key experiences in the development of students is associated with positive and immediate interactions between them and their teachers, through which they acquire beneficial educational experience and conduct a more successful academic and personal development (5). This survey of the contents of the various portfolios outlines a relatively new perspective on the background of the growing computerization of education - an emphasis on the direct contact between teachers and students. This shows another feature of the practice of the portfolio in the educational field - this practice contributes to the disclosure of otherwise unsuspected ways for continually improving the quality of education in the interest of collaboration between students and teachers.

According to A. Yarvinen of the Pedagogical Faculty of the University of Tampere, Finland, the assessment of the capacity for reflective and critical thinking in the stage of transition from education to the stage of "service", of real entering the working life, is a challenging task for the development of quality higher education. The best preparation for novice teachers, he says, is to organize, prepare their plans, observations and working models in the form of portfolio that reflects all their experience of education, observation and conducting of lessons controlled by assistant teachers. Within a year he conducted a study designed to assess the professional development in higher education based on personal portfolios developed during the relevant period. The participants in the study were students in their final year of training that is, on the threshold of entering professional life. The analysis of the surveys of the participants and their personal portfolios, made through qualitative methods, shows an extremely important result: that selfassessment and registration of one's own activity through a personal portfolio is the most important tool for professional development (6).

In the North American system of higher education the electronic portfolio is an established method for assessing, despite the concerns which exist about its validity in terms of its ability to carry out self-reflection and self-instruction as a manual. In one of the studies, students fill out questionnaires, which assess qualities associated with abilities that are required to achieve at the end of their graduation. In the last year of their training, the students who participated in the study (205248 students per year) are measured by means of their portfolios on the basis of their marks, feedback and the essays in which they describe the self-reflection on their training. In their essays in the form of portfolios, the students reflect their progress and make detailed 
plans for improvement. Progress in each area of study is evaluated, based on specific criteria and feedback, is provided. In their portfolios, the students gradually accumulate data about their studies related to the skills and qualities they expect to have achieved at their graduation. Providing a system which is well-enough structured, such as the portfolio, prevents the omission of significant areas of weaknesses and deficiencies in training. The requirement for self-evaluation and selfreflection at all stages of the evaluation system encourages students to reflect on their progress in their portfolios. It is indicated that the ePortfolio explicitly connects the results of students with the complex assessment which successfully implements self-regulation of the process of learning which would help them in their further professional activity (7).

An interesting and comprehensive study brought about new directions of electronic platforms. In an Australian university an institutional electronic tool called "iPortfolio" attracted over 17,000 subscribers one year after its introduction. The presented study determined how many students use this "iPortfolio", as well as the factors leading to its effective use. Through an online survey, conducted with 554 students, the competencies and technological skills, the motivating factors for using the platform, as well as its shortcomings, are tested. The survey results are examined in the context of the usage patterns of the database that is automatically collected for operational and administrative purposes. A statistically significant difference was not found with respect to the previous technological competence of the students or their self-esteem, compared to those not using the platform. It was definitely established, however, that assessment is the main driving force for creating an account in the institutional portfolio ("iPortfolio") of the University. However, about 42.9 per cent of the students admit they are likely to use "iPortfolio" in the future, even if it is not a requirement of the course, while 29.6 percent of the students do not take a definite position. No significant use of "iPortfolio" to accommodate the extracurricular activities was established. More than half of the students (52\%) say that their chances of finding a job have increased thanks to their inclusion in the university institutional electronic instrument. The recommendations made by the students were: to promote the inclusion in the platform, which would increase their competitiveness and improve their training in the university formal education (8).

In the complicated new situation of living, the quality of education is difficult to achieve and the perception of students of its effectiveness, on the one hand, and the indicators used for assessing good teaching, on the other, do not always overlap. Adding a third, no less important component in the chain of learnerseducators-market outlets, it becomes more necessary for the educational institutions to apply adequate methods and efforts to improve the training, to adapt to the digitalized new generations of students and find ways for increasing their inspiration and motivation (9).

As part of the sphere of services in education, three New Zealand universities agreed to develop a program for an electronic portfolio. In order to ensure conditions for its implementation and to develop guidelines for its use, the literature on ePortfolio and more traditional portfolios on paper were reviewed. This literature review focuses on the use of portfolio in higher education as a whole. However, as teacher preparation turns out to be the area that is most advanced in terms of using electronic portfolios, the majority of the overall conclusions and allegations on portfolios were composed on the basis of pedagogical literature. The publication even infers that the other university disciplines should learn from the practices in teacher education, as future teachers are adapted to using the portfolio, making the work of teaching transparent and accessible. The author of the published study also makes the important conclusion that, although research on electronic portfolios is still relatively new and insufficient, most studies so far have focused on their use for training and development of teachers. The fact is pointed out that electronic portfolios must be electronic versions of paper ones, as for both versions are valid three major components: purpose, methodology and evaluation. In view of this argument, the discussion, according to $\mathrm{P}$. Butler, should be focused on the following portfolio elements: different types and their uses; benefits; problems, questions and problems that arise in connection with their use; the main elements that must be present in their design to ensure their success on training, development of tools for evaluating performance, advantages and disadvantages to paper portfolio. In adopting the ePortfolio as a medium for the teaching of students, some of its characteristics guarantee success, but there are always some educational and technical barriers to its implementation (10). 
A survey conducted among medical students from the United Kingdom, aims to measure the absorption and utilization of e-portfolio for learning in terms of the support that it ensures for a continuous professional development, and to characterize the attitude to its use and the barriers in from of its adoption. All registered students were offered a year of a free trial period to lead a PC diary. Those who accepted underwent a special training seminar and the main results, subjected to quantitative and qualitative analysis, are derived from the answers to a simple questionnaire. Of the registered participants, 94\% completed the questionnaire. The PC diary was used by $34 \%$, but only $10 \%$ used it regularly. 54\% of the study participants asked to continue the subscription for the second year and 40\% asked what the opportunities for further training were. Among the responses received, extreme emotional responses were established - from dislike to a euphoric reception, often combined with allegations of an individual learning style. Among the leading obstacles to the use of the platform, the following were indicated: lack of time, lack of computer access and insufficient computer literacy. The main conclusion from this research is the need for a significant support for such implementation of reflection on training as using an electronic portfolio provides. The use and availability were influenced by the individual style of learning resources, training and technical support, which were often insufficient. A significant deficiency was also stated to be the imbalance between workload requirements and support provided, which is not conducive to the reflective type of training $(3-11)$.

Based on extensive research in the contemporary development of higher education, C. Klenovski emphasizes the enormous benefits of using portfolios for training and professional development in higher education. Recent scientific discoveries related to training, evaluation and selfassessment of students, dominating the literature on reflexive practice, according to the author, insufficiently provide guidance on how to use the portfolio for learning, development and understanding of one's own experience or evaluation of professional practices. Exploring the opportunities of the portfolio in this not very well studied field, based on three occasions (case studies), he comes to essential conclusions on the use of portfolios in terms of the set goals: the importance of identifying specific targets of the portfolio; impact of the use of the portfolio in terms of approaches to learning, teaching and professional development; changes in the professional practice caused as a result of training and the need to address issues related to ethics and confidentiality (8).

\section{CONCLUSION}

In the specialized literature, the process of developing electronic teaching portfolios is determined in two ways: supporting the longterm professional development: the process of multimedia development (decide/assess, design/plan, development, implementation, evaluation) and a process of development of a portfolio (collection, selection, reflection, projection/direction, presentation). A further definition of the development process of an eportfolio comprises of the following steps: 1 ) determination of the context and objectives of the portfolio; 2) preparing the work portfolio; 3) portfolio for the realization of reflection; 4) connectedness in a whole portfolio; 5) portfolio performance. In addition, there are at least five levels of technology used to develop electronic portfolios based on the ease of use, including technologies that are suitable for all levels and stages. This combined process creates the basis for a powerful professional development (12).

The tool Institutional ePortfolio is widely used worldwide by leading educational institutions with the aim to present the current institutional production and greater efficiency of communication and educational practices. It provides a constructive, open and inclusive dialogue and exchange of information, ideas and practices, with which the specific activities of an organization are presented in time and in an attractive way and so they reach their users in an understandable professional language.

\section{REFERENCES}

1. https://www.paradisevalley.edu/alarchive/docs

2. Stefanova, M., G. Kamenova. /2010/. Institutional Portfolio (Department for Information and Training of Teachers), Sofia University "St. Kliment Ohridski": http://www.diuu.bg/ispisanie/broi22/22kt/2 $2 \mathrm{kt} 1 . \mathrm{htm}$

3. Dysthe, O. et al. Portfolio practices in higher education in Norway in an international perspective: macro-, mesoand micro-level, Volume 36, Issue 1, 2011

4. https://eric.ed.gov/?id=ED282491

5. Klein, S.P., Kuh, G., Chun, M. et al. Research in Higher Education, 2005, ISSN: 0361-0365, publisher Springer, Netherlands 
6. Jarvinen, A. Promoting Professional Development in Higher Education through Portfolio Assessment - In: Assessment \& Evaluation in Higher Education- Volume 31, Issue 3, 2006

7. O'Sullivan, A.J. Linking assessment to undergraduate student capabilities through portfolio examination in Assessment and Evaluation in Higher Education - Volume 37, Issue 3, Institute of Education Sciences, U.S. Department of Education, 2012

8. Klenowsky, V. Promoting Professional Development in Higher Education through Portfolio Assessment - in: Assessment and Evaluation in Higher Education - Volume 31, Issue 3, 2006
ZHELYAZKOVA Z.

9. Ramsden, P. Learning to Teach in Higher Educaion, RoutlegdeFalmer, Sydney, 2003

10.Butler, P. A Review Of The Literature On Portfolios And Electronic Portfolios, 2006 http://www.citeulike.org/group/2518/article $/ 1277760$

11.Dornan, T. et al. An electronic learning portfolio for reflective continuing professional development, 2002 -

http://onlinelibrary.wiley.com/doi/10.1046/j .1365-2923.2002.01278.x/full

12.Barrett, H. Electronic Teaching Portfolios: Multimedia Skills + Portfolio Development $=$ Powerful Professional Development. $2000-$ https://eric.ed.gov/?id=ED444514 